\title{
ГЕОЛОГИЧЕСКИЕ ФАКТОРЫ, ВЛИЯЮЩИЕ НА ОБВОДНЕНИЕ НЕФТЯНЫХ СКВАЖИН МАЛЫХ МЕСТОРОЖДЕНИЙ
}

Введение.

Материалы и методы исследований.
В статье рассмотрен вопрос обводнения скважин и подъема водонефтяного контакта (ВНК) на примере месторождений Северного Кавказа. Приведен характер обводнения скважин нефтяных месторождений в зависимости от подъема ВНК и положения абсолютных отметок нижних перфорационных отверстий.

Использованы промысловые данные, замеры проведенные в скважинах нефтяных месторождений Северного Кавказа, результаты экспериментальных и лабораторных исследований проведенный. Методы исследований заключаются в анализе и обобщении информации о комплексе гидродинамических характеристик пласта (на примере малых нефтяных месторождений Северного Кавказа), об источниках и характера поступления пластовых подошвенных и законтурных вод при эксплуатации скважин, основанных на изучении аналитических зависимостей между, пластовым давлением в гидродинамической системе, объемов отбора нефти и количества поступающей пластовой жидкости из законтурной области.

Результаты исследования

и их обсуждение. Изучены некоторые процессы обводнения нефтяных скважин на примере Воробьевской площади. Выявлены основные источники поступления вод при разработке нефтяных скважин. В результате контроля за разработкой нефтяных скважин Воробьевской площади установлено, что поступление воды в обводнившиеся скважины происходило по каналам вертикальных трещин. При пересечении вертикальных трещин с более проницаемыми горизонтальными и при наличии градиента давлений в призабойной зоне начиналось продвижение воды по горизонтальным трещинам к скважинам с последующим их обводнением. Рассмотрены изменение гидрохимических показателей проб воды, отобранных на разные даты в скважинах Воробьевской площади.

Выводы:

Установлено, что основным источником поступления воды при разработке нефтяных скважин площади являются пластовые подошвенные и законтурные воды, являющиеся частью седиментационного бассейна Восточно-Ставропольской впадины. В скважинах, находящихся внутри контура нефтеносности, источником поступления воды является вышележащий водоносный термальный пласт. Нефтяное месторождение приурочено к гидродинамической ловушке, то есть соответствует классической модели. Структурно-литологическая водоплавающая нефтяная залежь в северной части контролируется замещением трещиноватых коллекторов глинистыми аргиллитами, в юго-западной и восточной части площади водонефтяным контактом, проведенным по результатам испытания скважин. Режим разработки залежи при отборе нефти на начальном этапе обеспечивается за счет упругоемкости гидродинамической системы и далее за счет внедрения законтурных и подошвенных пластовых вод. Падение пластового давления в гидродинамической системе месторождения зависит от объемов отбора нефти и поступления пластовой воды из законтурной области. Состояние гидродинамической системы месторождения зависит от внедрения подошвенных и законтурных пластовых вод. ционное отверстие, вертикальные трещины, абсолютная отметка, свита, отбор нефти, коэффициент корреляции. 
Gasumov R.A., Gasumov E.R.

North Caucasus Federal University, Stavropol, Russia Azerbaijan State University of Oil and Industry, Baku, Azerbaijan

\section{Geological Factors Influence on Oilwells Flooding at Small Fields}

Introduction.

The article discusses the issue of wells flooding and rise of the oil-water contact (WOC) by the example of North Caucasus fields. Flooding character of oil fields wells is given depending on rise of oil-water contact and the position of absolute levels for lower perforation holes.

Materials and research methods.

Field data, measurements taken in the wells of oil fields in the North Caucasus, the results of experimental and laboratory studies are used. The research methods consist in analyzing and summarizing information about the complex of reservoir hydrodynamic characteristics (for example, small oil fields in the North Caucasus), about the sources and nature of the inflow of bottom and bottom water during the operation of wells based on the study of analytical relationships between formation pressure in the hydrodynamic system, volumes of oil withdrawal and the amount of incoming formation fluid from the peripheral zone.

Research results and discussion.

Conclusions.

Key words:
Some processes of oil wells flooding were studied by the example of Vorobyevskaya area. The main sources of water inflow during the development of oil wells are identified. As a result of control over the development of oil wells of Vorobyevskaya area, it was established that the flow of water into the waterlogged wells occurred through vertical fracture channels. At the intersection of vertical fractures with more permeable horizontal fractures and in the presence of a pressure gradient in the bottomhole zone water began to move along the horizontal fractures to the wells with their subsequent flooding. Changes in the hydrochemical parameters of water samples taken at different dates in the wells of Vorobyevskaya area are considered.

It has been established that the main source of water inflow during the development of the area's oil wells is formation bottom and peripheral waters which are part of the sedimentation basin of the East Stavropol Depression.

In wells located inside oil-drainage line the source of water is the overlying aquifer thermal layer. The oil field is confined to a hydrodynamic trap that is it corresponds to the classical model. The structural and lithological floating oil reservoir in the northern part is controlled by the replacement of fractured reservoirs with clay mudstones, in the southwestern and eastern parts of the area with oil-water contact carried out according to the results of well testing. The mode of reservoir development during oil withdrawal at the initial stage is ensured by the elastic capacity of the hydrodynamic system and then through the introduction of peripheral and bottom formation waters. The drop in reservoir pressure in the field hydrodynamic system depends on the volume of oil withdrawal and inflow of formation water from the peripheral zone. The state of field hydrodynamic system depends on the introduction of bottom and peripheral formation waters.

well, water, flooding, water-oil contact, oil content, operation, perforation hole, vertical fractures, absolute level, formation, oil withdrawal, correlation coefficient. 


\section{Введение}

Обводнения скважин и подъем водонефтяного контакта (ВНК) характерен для большинство месторождений Северного Кавказа. Обводнение скважин этих месторождениях (площадях) происходило по мере подъема ВНК поочередно, начиная со скважин с более низким положением абсолютных отметок нижних перфорационных отверстий.

Из эксплуатационных скважин первой начала обводняться скважина, находящаяся вблизи внешнего контура нефтеносности. При подъеме ВНК от нижних перфорационных отверстий (НПО) до верхних перфорационных отверстий (ВПО) одни скважины выбыли из эксплуатации, вследствие обводнения, а другие скважины начинались обводняться при подъеме ВНК до отметки НПО. Она обводнилась при достижении ВНК верха перфорации.

Скважины, в которых ВНК не достиг верхних перфорационных отверстий, эксплуатировались с обводненностью продукции, возрастающей с течением времени по мере подъема ВНК. Исключением являлась скважины, которых обводнялись при достижении ВНК низа перфорации с содержанием воды $65-90 \%$.

Внедрение воды в условиях проявления упруго-водонапорного режима происходило по вертикальным трещинам. Этот период разработки характеризуется низкими темпами падения пластового давления - около 0,1 МПа в год и подъемом ВНК по всей площади с последовательным обводнением скважин с более низкими отметками интервалов перфорации. Наблюдалось изменение характера поступления воды с продукцией из скважин в виде свободной воды при ее содержании до 10-15\%, затем в виде стойкой водонефтяной эмульсии с содержанием в ней (28-65\%) воды в качестве фазы в нефтяной среде. Объемы поступления пластовой воды с нефтью на поверхность были невелики из-за низких общих объемов поступления жидкости из скважин.

\section{Материалы и методы исследований}

В статье использованы промысловые данные, замеры проведенные в скважинах нефтяных месторождений Северного Кавказа, результаты экспериментальных и лабораторных исследований проведенный. Методы исследований заключаются в анализе и обобщении информации о комплексе гидродинамических характеристик пласта (на примере малых нефтяных месторождений Северного Кавказа), об источниках и характера поступления пластовых подошвенных и законтурных вод при эксплуатации скважин, основанных на изучении аналитических зависимостей между, пластовым давлением в гидродинамической системе, объемов отбора нефти и количества поступающей пластовой жидкости из законтурной области.

Для освещения гидродинамической картины использованы пластовые давления по месторождениям и площадям, где из хадумской и баталпашинской свит получены притоки нефти. Дополнительно привлечены также дан- 
ные по определению коэффициентов аномальности поровых давлений, подсчитанных на основании геофизических исследований скважин. Характерной особенностью гидродинамики седиментационного бассейна исследуемого района по сравнению с инфильтрационным является движение пластовых вод из глубоко погруженных зон к периферийным участкам впадин.

В связи, чем изучения источников поступления воды, внедрение пластовых подошвенных и законтурных вод, являющиеся частью седиментационного бассейна Восточно-Ставропольской впадины при разработке нефтяных скважин нефтяных месторождений (площади), являются актуальной задачей.

\section{Результаты исследования и их обсуждение}

Для нефтяных месторождений Северного Кавказа основным критерием формирования залежей нефти является классическое положение о том, что накопление органического вещества, превращение его в микронефть и дальнейшая латеральная и вертикальная миграция углеводородов (УВ) происходят медленно, но в условиях движущейся водной среды $[1,2]$.

Пластовые воды Воробьевского месторождения относятся к третьей гидрогеохимической зоне, характеризующейся аномально-высокими пластовыми давлениями (АВПД), наличием хлоркальциевых вод с минерализацией 20-35 г/дм³ . В связи с наличием АВПД, обычно характерных для изолированных бассейнов, хадум-баталпашинские водоносные отложения следует относить к зоне весьма затрудненного водообмена. Движение и скорость потока пластовых вод будут определяться количеством воды, поступающей из зон с максимальным значением пластовых давлений и испытывающих современное погружение. Трещиноватые аргиллиты, слагающие здесь хадумскую и баталпашинскую свиты, залегают на глубинах свыше 3000 м, имеют высокие пластовые температуру $\left(140-150^{\circ} \mathrm{C}\right)$ и АВПД (коэффициент аномальности 1,3-1,8). Разгрузка пластовых вод исследуемых горизонтов происходит в бортовых частях указанных впадин по скрытым тектоническим нарушениям. Региональная гидродинамическая характеристика олигоценовых отложений основывается на замерах пластовых давлений по отдельным поисковым площадям и открытым месторождениям.

В ряде скважин в разрезе нижнего майкопа отмечаются водонасыщенные пласты, которые залегают выше баталпашинского репера.

Так, из эксплуатационных скважин первой начала обводняться скважина, находящаяся вблизи внешнего контура нефтеносности [3-5]. При подъеме водонефтяного контакта (ВНК) от верхних перфорационных отверстий (НПО) с абсолютной отметкой -1932,2 м до верхних перфорационных отверстий (ВПО) с отметкой -1896,2 м скважина выбыла из эксплуатации вследствие обводнения (более 50 \% пластовой воды в продукции). А другая скважина начала обводняться при подъеме ВНК до отметки НПО -1892 м. Она обводнилась при достижении ВНК верха перфорации с отметкой -1878 м. 
Скважины, в которых ВНК не достиг верхних перфорационных отверстий, эксплуатировались с обводненностью продукции, возрастающей с течением времени по мере подъема ВНК. Исключением являлись скважины, которые обводнялись при достижении ВНК низа перфорации с содержанием воды $65-90 \%$.

Внедрение воды в условиях проявления упруго-водонапорного режима происходило по вертикальным трещинам $[5,6]$. Этот период разработки характеризуется низкими темпами падения пластового давления - около 0,1 МПа в год и подъемом ВНК по всей площади с последовательным обводнением скважин с более низкими отметками интервалов перфорации. Наблюдалось изменение характера поступления воды с продукцией из скважин в виде свободной воды при ее содержании до $10-15 \%$, затем в виде стойкой водонефтяной эмульсии с содержанием в ней (28-65 \%) воды в качестве фазы в нефтяной среде. Объемы поступления пластовой воды с нефтью на поверхность были невелики из-за низких общих объемов поступления жидкости из скважин.

В результате контроля за разработкой нефтяных скважин Воробьевской плошади установлено, что поступление воды в обводнившиеся скважины происходило по каналам вертикальных трещин [6-8]. При пересечении вертикальных трещин с более проницаемыми горизонтальными и при наличии градиента давлений в призабойной зоне начиналось продвижение воды по горизонтальным трещинам к скважинам с последующим их обводнением (табл. 1).

За пятнадцать лет эксплуатации суммарный отбор нефти из баталпашинской и хадумской свит Воробьевской площади составил 109682,5 т; объем внедрившейся в залежь воды оценивается в 120 тыс. м³. Подъем ВНК составил порядка $100 \mathrm{~m}$, средняя скорость подъема ВНК составляет 9,1 м/год. Выявлено, что темп продвижения воды определяется отбором нефти. По вышеприведенным данным построена зависимость подъема ВНК от отборов нефти на Воробъевской площади (рис. 1). Установлена логарифмическая зависимость подъема ВНК от отборов нефти, коэффициент корреляции 0,9862. В соответствии с выявленной зависимостью можно прогнозировать подъем ВНК и для Журавской площади данного региона.

Вода, отобранная из обводнившихся скважин, по составу аналогична пластовой воде, полученной из разведочных скважин, пробуренных за пределами нефтяной залежи (табл. 2).

Рассмотрим изменение гидрохимических показателей проб воды, отобранных на разные даты в скважинах Воробьевской площади. Для хадумской свиты пластовая вода, полученная из законтурной зоны вблизи ВНК, имеет минерализацию $23,3-27,6$ г/дм², относится к хлоридно-кальциевому типу, $\mathrm{pH}=6,5-7,2$.

По мере подъема ВНК и продвижения пластовых вод в северном направлении, скважина обводнялась. Проба воды, отобранная из скважины 
Таблица 1. ДОБЫЧА НЕФТИ И ДАННЫЕ ПО ОБВОДНЕНИЮ ЭКСПЛУАТАЦИОННЫХ СКВАЖИН ВОРОБЬЕВСКОЙ ПЛОЩАДИ Table 1. Oil production and flooding data for recovery wells of the Vorobievskaya area

\begin{tabular}{l|l|l|l|l}
\hline $\begin{array}{l}\text { Год } \\
\text { эксплу- } \\
\text { атации }\end{array}$ & $\begin{array}{l}\text { Возраст } \\
\text { (свита) }\end{array}$ & $\begin{array}{l}\text { Содержание воды } \\
\text { в продукции, } \\
\%\end{array}$ & $\begin{array}{l}\text { Состояние скважины } \\
\text { жело- } \\
\text { ВНК }\end{array}$ \\
\hline
\end{tabular}

Скважина №1, Alp = 303,2 м, интервал перфорации, абсолютная отметка -1849,8-1883,8 м

\begin{tabular}{|c|c|c|c|c|}
\hline 9 & хадум-баталпашинская & до 19 & эксплуатация & -1848 \\
\hline 4 & хадум-баталпашинская & до 73 & эксплуатация с обводнением & -1846 \\
\hline 2 & хадум-баталпашинская & до 95 & выход из эксплуатации & -1844 \\
\hline
\end{tabular}

Скважина № 2, Alp = 252,3 м, интервал перфорации, абсолютная отметка -1881,7-1903,7 м

\begin{tabular}{|c|c|c|c|c|}
\hline 4 & хадум & до 5 & эксплуатация & -1916 \\
\hline 4 & хадум & до 50 & эксплуатация с обводнением & -1894 \\
\hline 2 & хадум & - & выход из эксплуатации & -1861 \\
\hline
\end{tabular}

Скважина № 5, Alp = 200,8 м, интервал перфорации, абсолютная отметка, -1907,2-1917 м

\begin{tabular}{|c|c|c|c|c|}
\hline 3 & хадум & 0 & эксплуатация & -1935 \\
\hline 9 & хадум & $0-95$ & эксплуатация с обводнением & -1916 \\
\hline
\end{tabular}

Скважина № 6, Alp = 217,8 м, интервал перфорации, абсолютная отметка, -1896,2-1913,2 $-1913,2-1932,2$

\begin{tabular}{|c|c|c|c|c|}
\hline 4 & хадум-баталпашинская & $0-50$ & эксплуатация с обводнением & -1894 \\
\hline 1 & хадум-баталпашинская & до $>50$ & обводнение & -1884 \\
\hline
\end{tabular}

Скважина № 9, Alp = 269,0 м, интервал перфорации, абсолютная отметка, -1878-1892м

\begin{tabular}{|c|c|c|c|c|}
\hline 3 & хадум & - & эксплуатация & -1904 \\
\hline 1 & хадум & до 20 & эксплуатация с обводнением & -1894 \\
\hline 1 & хадум & до 50 & обводнение & -1884 \\
\hline
\end{tabular}

Скважина № 15, Alp = 169,8 м, интервал перфорации, абсолютная отметка, -1830,2-1850,2 м

\begin{tabular}{l|llll}
2 & баталпашинская & - & эксплуатация & $\frac{-}{\text { эксплуатация с обводнением }}$ \\
\cline { 1 - 3 } & баталпашинская 65 & $\frac{1}{-1848}$
\end{tabular}

Скважина № 29, Alp = 288,8 м, интервал перфорации, абсолютная отметка, -1846,2-1861,2

\begin{tabular}{|c|c|c|c|c|}
\hline 2 & баталпашинская & - & эксплуатация & -1884 \\
\hline 2 & баталпашинская & до 25 & эксплуатация & -1873 \\
\hline 1 & баталпашинская & до 50 & обводнение & -1850 \\
\hline
\end{tabular}

Скв. № 6 Южно-Спасская, Alp = 259,8 м, интервал перфорации, абсолютная отметка, -1832,2-1845,2

\begin{tabular}{l|llll}
\hline 11 & баталпашинская & $\frac{-}{65-90}$ & $\frac{\text { эксплуатация }}{\text { баталпашинская }}$ & $\frac{\text { боднение }}{-1848}$ \\
\hline
\end{tabular}




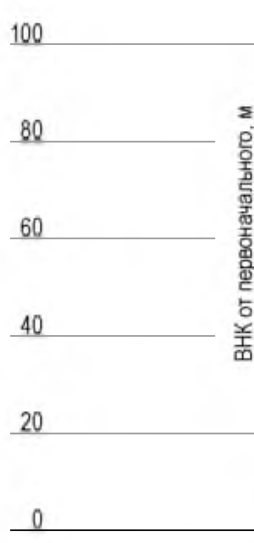

Таблица 2.

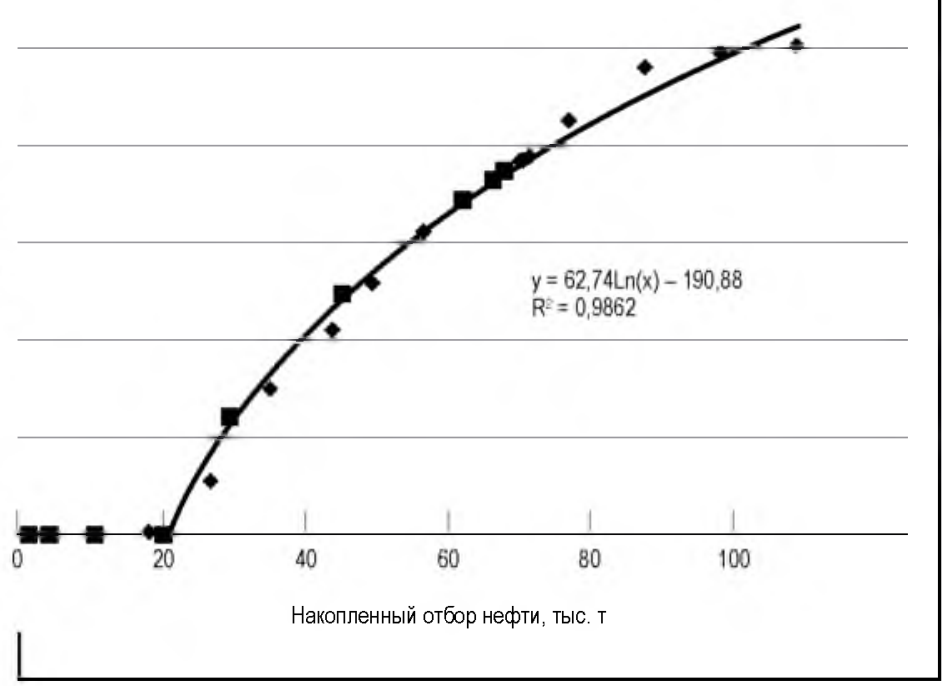

\section{Зависимость подъема ВНК от отбора нефти}

Figure 1. Dependence of water-oil contact rise on oil withdrawal.

СРАВНИТЕЛЬНАЯ ХАРАКТЕРИСТИКА СОСТАВА ВОД, ПОЛУЧЕННЫХ ИЗ СКВАЖИН ВОРОБЬЕВСКОЙ ПЛОЩАДИ Table 2. Comparative description of water composition from the Vorobievskaya area wells

\begin{tabular}{|c|c|c|c|c|c|}
\hline \multirow[t]{2}{*}{$\begin{array}{l}\text { Группа и номер } \\
\text { скважины }\end{array}$} & \multirow[t]{2}{*}{$\mathrm{pH}$} & \multirow[t]{2}{*}{$\begin{array}{l}\text { Плотность } \\
\text { воды, кг/M³ }\end{array}$} & \multirow{2}{*}{$\begin{array}{l}\text { Общая } \\
\text { минерализация, } \\
\text { г/дм³ }\end{array}$} & \multicolumn{2}{|c|}{$\begin{array}{l}\text { Содержание характерных } \\
\text { компонентов, г/дм³ }\end{array}$} \\
\hline & & & & $\mathrm{K}+\mathrm{Na}$ & $\mathrm{Cl}$ \\
\hline $\begin{array}{l}\text { Скважины, } \\
\text { обводнившиеся } \\
\text { при добыче } \\
\text { нестти }\end{array}$ & $6,35-7,6$ & $1016-1022$ & $23,2-28,0$ & $7,931-9,746$ & $11,13-15,69$ \\
\hline $\begin{array}{l}\text { Скважины, } \\
\text { обводнившиеся } \\
\text { в ходе ожидания } \\
\text { подключения }\end{array}$ & $6,0-7,2$ & $1018-1019$ & $28,2-29,7$ & $7,900-10,51 !$ & $12,0-16,8$ \\
\hline $\begin{array}{l}\text { Скважины, давшие } \\
\text { несть с водой } \\
\text { при опробовании } \\
\text { после бурения }\end{array}$ & $6,4-6,7$ & $1016-1020$ & $23,28-32,97$ & $6,92-12,8$ & $13,6-19,9$ \\
\hline $\begin{array}{l}\text { Разведочные } \\
\text { скважины, } \\
\text { давшие притоки } \\
\text { воды }\end{array}$ & $5,7-7,0$ & $1015-1024$ & $23,42-27,58$ & $7,339-10,06$ & $13,29-19,12$ \\
\hline
\end{tabular}


вблизи текущего положения ВНК, имеет минерализацию 23,2 г/дм³ но-кальциевый тип, $\mathrm{pH}=7,6$. Дальнейшее продвижение воды на этом участке характеризуется двумя пробами, отобранными из скважин, имеющих минерализацию 26,6 и 26,4 г/дм³ соответственно и хлоридно-кальциевый тип. Поскольку ВНК на этот период находился севернее, в районе скважины, то вероятно, обводнение произошло водой, поступившей из законтурной зоны. На западном участке площади имеются данные по трем скважинам, две из них находились за пределами первоначального контура нефтеносности, а одна скважина Воробьевская - вблизи его. Сравнение показателей рН показывает, что вода из этой скважины, прошедшая через нефтяную часть пласта, имеет более низкое значение $\mathrm{pH}=6,7$, чем вода из законтурной зоны $(\mathrm{pH}=7,2)$.

Повышение шелочности пластовых вод при фильтрации через зону нефтенасыщения подтверждается сравнением химических анализов проб воды, имеющих равную минерализацию и относящихся к хлоридно-магниевому типу, отобранных из интервала баталпашинской свиты [8-10]. Вода из скважины вблизи внешнего контура нефтеносности имеет минерализацию 28,0 г/ дм $^{3}, \mathrm{pH}=7,1$. Проба воды, отобранная из скважины вблизи текущего ВНК, имеет $\mathrm{pH}=6,4$; в ионном составе отмечается увеличение концентраций катионов натрия и кальция. В скважине, находящейся внутри ВНК, из интервала баталпашинской свиты получена вода с минерализацией 25,8 г/дм ${ }^{3}, \mathrm{pH}=7,0$, тип воды хлоридно-магниевый. Источником обводнения скважин Воробьевской площади, вероятно, является верхний водоносный пласт, поскольку глинистый раздел отсутствует в разрезе. Скорость подъема ВНК по данным, составляет максимально 2 м/год, таким образом, ВНК должен находиться на абсолютной отметке $-1840 \mathrm{M}$.

В скважине Воробъевской площади, находящейся также внутри текущего контура ВНК, получена вода хлоридно-кальциевого типа с минерализацией 33,8 г/дм ${ }^{3}, \mathrm{pH}=6,5$. Абсолютная отметка ВНК составляет -1844 м, НПО на отметке минус 1782 м. Теоретически, возможно подтягивание конуса пластовой воды в результате эксплуатации скважины.

Поскольку законтурная вода в баталпашинской свите относится к хлоридно-кальциевому и хлоридно-магниевому типам, а вода, полученная в скважине Воробьевская, имеет гидрокарбонатно-натриевый тип, то более вероятно обводнение из вышележащего водоносного пласта.

Верхний водоносный пласт проявлял себя в скважине Воробьевской площади, где из интервала 1860-1870 м (выше баталпашинского репера на 211 м) получена вода с температурой $95{ }^{\circ} \mathrm{C}$ и минерализацией 15,7 г/дм ${ }^{3}$. Вода сильно щелочная с большим содержанием карбонат - иона $(0,792$ г/дм³ $)$ и гидроксил - иона $(0,350$ г/дм³ $)$. Ниже по разрезу этой скважины в интервале $1996-$ 2020 м (на 51 м выше баталпашинского репера) по каротажу выделяется водонасыщенный пласт, состоящий из пяти пропластков, который не опробован. 
При опробовании интервала 2065-2098 м в скважине (выше репера на 30 м) получен незначительный приток воды гидрокарбонатно-натриевого типа с минерализацией 9,8 г/дм². А в скважине в интервале 1940-1974 м, где залегает водоносный пласт, представленный переслаиванием аргиллитов и алевролитов различной степени глинистости, выделяется пять пропластков. Пласт находится выше баталпашинского репера на 30 м и не был опробован в скважине. Однако, в процессе добычи нефти из баталпашинской свиты в продукции скважины появилась вода с минерализацией 25,5 г/дм³ ${ }^{3}$ гидрокарбонатно-натриевого типа, который характерен для вышезалегающего водоносного интервала.

Водоносный пласт нижнего майкопа, залегающий выше термального, опробован в скважинах, где из интервала 1895-1910 м (на 202 м выше баталпашинского репера) получена вода с минерализацией 24,8 г/дм³, гидрокарбонатно-натриевого типа. Термальный пласт выделяется по каротажу в интервале 2025-2058 м, состоит из пяти пропластков.

В другой скважине из интервала 1910-1938 м получен переливающий приток воды с газом, $\mathrm{Q}_{\mathrm{B}}=10,0 \mathrm{~m}^{3} / \mathrm{cyт}, \Gamma=1786 \mathrm{~cm}^{3} / \mathrm{gm}^{3}$, тип воды хлоридномагниевый, минерализация 26,3 г/дм³. Термальный пласт, состоящий из четырех пропластков, выделяется по каротажу в интервале 2014-2041 м, на 68 м выше остракодового пласта.

Основным источником поступления воды при разработке нефтяных скважин площади являются пластовые подошвенные и законтурные воды, являющиеся частью седиментационного бассейна Восточно-Ставропольской впадины. Имеется основание предполагать, что в скважинах, находящихся внутри контура нефтеносности, источником поступления воды является вышележащий водоносный термальный пласт, а выше баталпашинского репера на 20-50 м и на 100-200 м залегают водонасыщенные пласты.

Нефтяное месторождение приурочено к гидродинамической ловушке, то есть соответствует классической модели. Структурно-литологическая водоплавающая нефтяная залежь в северной части контролируется замещением трещиноватых коллекторов глинистыми аргиллитами, в югозападной и восточной части площади водонефтяным контактом, проведенным по результатам испытания скважин. Режим разработки залежи при отборе нефти на начальном этапе обеспечивается за счет упругоемкости гидродинамической системы и далее за счет внедрения законтурных и подошвенных пластовых вод. 
Падение пластового давления в гидродинамической системе месторождения зависит от объемов отбора нефти и поступления пластовой воды из законтурной области. Состояние гидродинамической системы месторождения зависит от внедрения подошвенных и законтурных пластовых вод.

\section{Библиографический список}

1. Гасумов Р.А. Исследования горно-геологических условий для проведения геологоразведочных работ в Предкавказье / Р.А. Гасумов, В.А. Гридин, В.Г. Копченков, Б.Ф. Галай, С.А. Дудаев // Записки Горного института. СПб., 2017. Т. 228. С. 654-661.

2. Гасумов Р.A. Влияние геологических факторов на качество крепления глубоких скважин / Р.А. Гасумов, С.Б. Бекетов, А.Г. Керимов, В.В. Федоренко, Б.Ф. Галай // «Строительство нефтяных и газовых скважин на суще и на море». М.: ВНИИОЭНГ, 2018. №1. С. 12-15.

3. Гасумов Р.А. Влияние геологических факторов на коллекторские свойства продуктивных пластов с трещиноватыми глинистыми коллекторами при их вскрытии бурением / Р.А. Гасумов, И.А. Керимов, В.М. Харченко // Строительство нефтяных и газовых скважин на суше и на море. 2018. №7. С. 28-32.

4. Гасумов Р.А. Влияние горно-геологических характеристик пласта на физико-химические процессы твердения тампонажного раствора при цементировании глубоких скважин / Р.А. Гасумов, Э.Р. Гасумов // Естественные и технические науки. М., 2018. №7 (121). C. 73-77.

5. Гасумов Р.А. Обоснование нефтегазонасыщенной толщины и проницаемости нижнемайкопских глинистых коллекторов (на примере месторождений Северного Кавказа) / Р.А. Гасумов // Нефтегазовая геология. Теория и практика. 2018. №3. Т. 13.

6. Гасумов Р.А. О непроницаемости глинистых коллекторов малых месторождений / Гасумов Р.А., И.А. Керимов, В.М. Харченко // Нефтепромысловое дело. М.: ВНИИОЭНГ, 2018. №8. С. 46-52.

7. Гасумов Р.А. Выделение и оценка фильтрационно-емкостных параметров глинистых коллекторов / Гасумов Р.А. // Научный журнал «Наука. Инновации. Технологии». Ставрополь: СКФУ. 2018. № 2. C.115-126.

8. Гасумов Р.А. К вопросу об определении положения водонефтяного контакта при освоении малых месторождений (на примере Журавско-Воробьевского нефтяного месторождения) / Р.А. Гасумов // Булатовские чтения: материалы II Международной научно-практической конференции (Краснодар, 2018.). Краснодар: Издательский дом «ЮГ», 2018. Т. 2. Ч. 1. С. 131-136. 
9. Гасумов Р.А. Причины отсутствия притоков пластовых фрлюидов при освоении скважин малых месторождений (на примере хадум-баталпашинского горизонта) / Р.А. Гасумов // Научный журнал. Записки горного института. СПб., 2018. Т. 234. С. 630-636.

10. Гасумов Р.А. Повышение эффективности разработки газоконденсатных месторождений за счет применения инноваций / Р.А. Гасумов, Э.Р. Гасумов // Булатовские чтения: материалы III Международной научно-практической конференции (31.03.2019): Т. 2: сборник статей. Краснодар: Издательский дом «Юг», 2019. С. 55-63.

\section{References}

1. Gasumov R.A. Research of geological conditions for geological exploration in the Ciscaucasia / Gasumov R.A., Gridin V.A. Kopchenkov V.G., Galay B.F., Dudaev S.A. // Notes of the Mining Institute. SPb., 2017. Vol. 228. P. 654-661.

2. Gasumov R.A. The influence of geological factors on the quality of deep wells casing / Gasumov R.A., Beketov S.B., Kerimov A.G., Fedorenko V.V., Galay B.F. // Construction of oil and gas wells overland and at sea. M.: VNIIOENG, 2018. No. 1. P. 12-15.

3. Gasumov R.A. The influence of geological factors on the reservoir properties of formations with fractured clay reservoirs when they are opened by drilling / R.A. Gasumov, I.A. Kerimov, V.M. Kharchenko // Construction of oil and gas wells overland and at sea. 2018. No. 7 , p. 28-32.

4. Gasumov R.A. The influence of mining and geological characteristics of the reservoir on the physicochemical processes of cement slurry hardening during cementing deep wells / Gasumov R.A., Gasumov E.R. // Natural and technical sciences. M., 2018. No. 7 (121), p. $73-77$.

5. Gasumov R.A. Justification of the oil and gas-saturated thickness and permeability of the Lower Maykop clay reservoirs (by the example of deposits in the North Caucasus) / Gasumov R.A. // Oil and gas geology. Theory and practice. 2018. No. 3. Vol.13.

6. Gasumov R.A. On the impermeability of clay reservoirs of small deposits / Gasumov R.A., Kerimov I.A., Kharchenko V.M. // Oilfield business. M.: VNIIOENG, 2018. No. 8, p. 46-52.

7. Gasumov R.A. Determination and evaluation of filtration-capacitive parameters of clay reservoirs. / Gasumov R.A. // Scientific journal "Science. Innovation Technologies".-Stavropol: SKFU. 2018 No. 2. p.115-126.

8. Gasumov R.A. On the issue of determining the position of the oilwater contact during the development of small fields (by the example of the Zhuravsko-Vorobievskoye oil field) / Gasumov R.A. // Bulatov readings: materials of the II International Scientific and Practical Conference (Krasnodar, 2018.). Krasnodar: Publishing House-South, 2018. Vol. 2. Part 1. P. 131-136. 
9. Gasumov R.A. The reasons for the lack of formation fluid inflows during the development of wells in small fields (for example, the Khadum-Batalpashinsky horizon) / Gasumov R.A. // Science Magazine. Notes of the Mining Institute. SPb., 2018. Vol. 234. P. 630636.

10. Gasumov R.A. Improving the efficiency of gas condensate field development through the use of innovations / Gasumov R.A., Gasumov E.R. // Bulatov readings: materials of the III International Scientific and Practical Conference (03/31/2019): Vol. 2: collection of articles. Krasnodar: Publishing House-South. 2019. P. 55-63.

Поступило в редакцию 10.10.2019, принята к публикации 02.12.2019

\section{O6 авторах}

Гасумов Рамиз Алиджавад-оглы, доктор технических наук, профессор, заведующий кафедрой проектирование объектов в нефтегазовой сфере, Северо-Кавказский федеральный университет, Ставрополь, Россия. E-mail: r.gasumov@yandex.ru

Гасумов Эльдар Рамизович, кандидат экономических наук, доцент кафедры менеджмента, Азербайджанский государственный университет нефти и промышленности, Баку, Азербайджан. E-mail: Priemnaya@scnipigaz.ru

\section{About the authors}

Gasumov Ramiz Alidgavad-ogly, Doctor of Technical Sciences, Professor, North Caucasus Federal University, Stavropol, Russia. E-mail: r.gasumov@yandex.ru

Gasumov Eldar Ramizovich, Candidate of Economic Sciences, Associate Professor, Azerbaijan State University of Oil and Industry, Baku, Azerbaijan. E-mail: Priemnaya@scnipigaz.ru 